\title{
KERATO-ACANTHOMA IN OCULAR PATHOLOGY
}

\author{
BY \\ D. RENÉ BARRY \\ Department of Pathology, Institute of Ophthalmology, University of London
}

THE main interest of kerato-acanthoma (molluscum sebaceum) is its resemblance to squamous-cell carcinoma of the skin: it is, however, benign and even self-healing, and it seems very likely that an appreciable number of lesions diagnosed as malignant in the past, and followed-up as such, were in fact examples of this condition, so that a mistaken diagnosis may result in gross over-treatment and in statistical and prognostic errors in assessing skin tumours. Since the description of the original series by MacCormac and Scarff (1936), many papers have appeared in the general literature. As regards ocular conditions, Beare (1953), analysing a series of 76 cases of kerato-acanthoma, found that ten of these occurred in the skin of lids or canthi, or in the vicinity of the eye. In the American ophthalmic literature, Christensen and Fitzpatrick (1955) and Givner, Kallos, Medine, and Orfuss (1960) have reported similar cases, and Freeman, Cloud, and Knox (1961) reported the first case of kerato-acanthoma of the conjunctiva.

The lesion can occur in either sex, and is commoner in the older age groups; tar has been mentioned as a factor in kerato-acanthoma in general, but it is not known if this plays a part in the site under review. There is no evidence available of a virus origin.

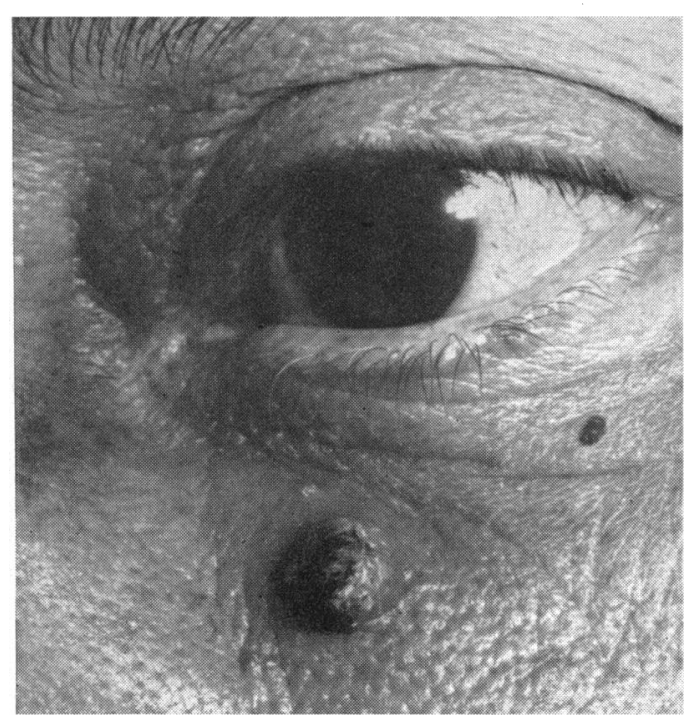

As distinct from multiple self-healing squamous carcinoma (Ferguson Smith, 1934), a kerato-acanthoma is usually single and appears as a papule in previously normal skin; the growth enlarges rapidly, becoming a raised nodule with a round edge, and attaining a diameter of 1 or $2 \mathrm{~cm}$. in only 6 to 8 weeks (Fig. 1).

FIG. 1.-Kerato-acanthoma-clinical appearance.

* Received for publication October 25, 1961. 
The centre often consists of a crater filled with hard dry keratin. If left untouched, and even if a portion is taken for microscopy, the lesion loses its keratin, becomes flatter, and in a matter of months, 4, 6, or rarely more, it regresses leaving a puckered scar.

Although a kerato-acanthoma may be mistaken for more commonplace lesions, the greatest difficulty is to distinguish it from an epidermoid carcinoma. The absence of involvement of the lymph nodes and of deep fixation is of little value in diagnosing an early lesion. The remarkably short history and the dryness of the crater, which does not ooze, are important diagnostic features.

Microscopy shows the elevation of the nodule above the epidermal line and, if the section is central, the shape is characteristic with a central crater containing keratin or parakeratin, lined by an acanthotic epithelium, giving rise to rounded downgrowths, rarely reaching beyond the hair follicles in the dermis where a chronic inflammatory reaction is usually present.

Histologically, the diagnostic problem is that of deciding whether the lesion is an epidermoid carcinoma, premalignant or benign. As mentioned by Lennox (1960), many students have been taught the histological appearances of epidermoid carcinoma on sections which have later been found to be specimens of kerato-acanthoma. The pseudo-invasion can mimic reality; the inflammatory response may mask the sharp epidermal-dermal boundary; the cytology may be atypical; and mitotic figures may be present if the lesion has been removed at a stage of intense growth. Furthermore, if the section is tangential owing to difficulty in orientation, or if the specimen is minute, as is common in biopsies of ocular tissues, there is the greatest likelihood of an erroneous diagnosis of malignancy being made: Lennox (1960) suggests that the diagnosis should be the result of consultation between the clinician and pathologist, rather than that each should try separately to reach his own conclusion.

In the management of the condition, excision may be indicated as it is considered the best treatment for cosmetic results (Borrie, 1961). Moreover, growth may continue beyond 8 or 9 weeks introducing doubts as to the diagnosis, so that excision should be as wide as the suspected nature of the lesion would justify. If, however, the clinical diagnosis of simple keratoacanthoma can be made with confidence, partial removal, such as paring down of all the protruding tissue followed by curetting, cauterizing, freezing, or electro-coagulation, is advised by most writers. This allows a limited histological examination which may be assessed in the full knowledge of the history, the stage of development of the lesion in weeks, and the clinical diagnosis. A clinical photograph would then be of particular value to the microscopist.

\section{Case Reports}

Case 1, a woman aged 66, presented with a large mass on the left lower lid which had been present for several weeks. It shelled out easily and had the appearance of a sebaceous cyst. 
The specimen consisted of two fragments, one measuring $8 \times 5 \times 9 \mathrm{~mm}$. and the other $6 \times 5 \times 2 \mathrm{~mm}$. (Figs 2 and 3 ).

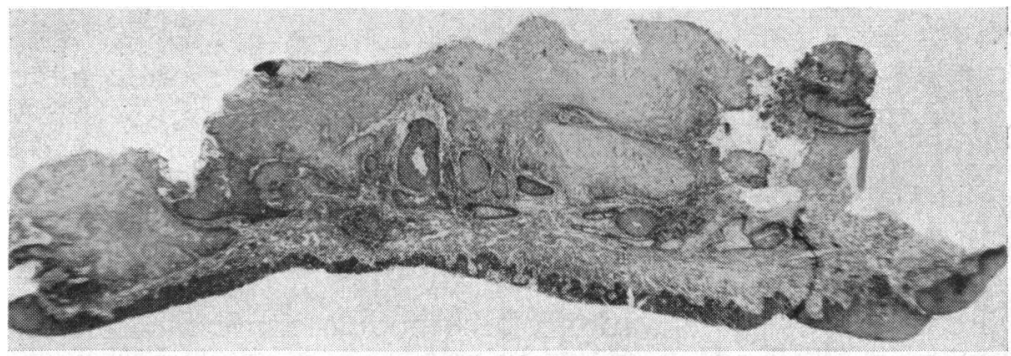

Fig. 2.-One of the fragments in Case 1. Proximity of tumour elements to conjunctival epithelium is shown on the left. Haematoxylin and eosin. $\times 16$.

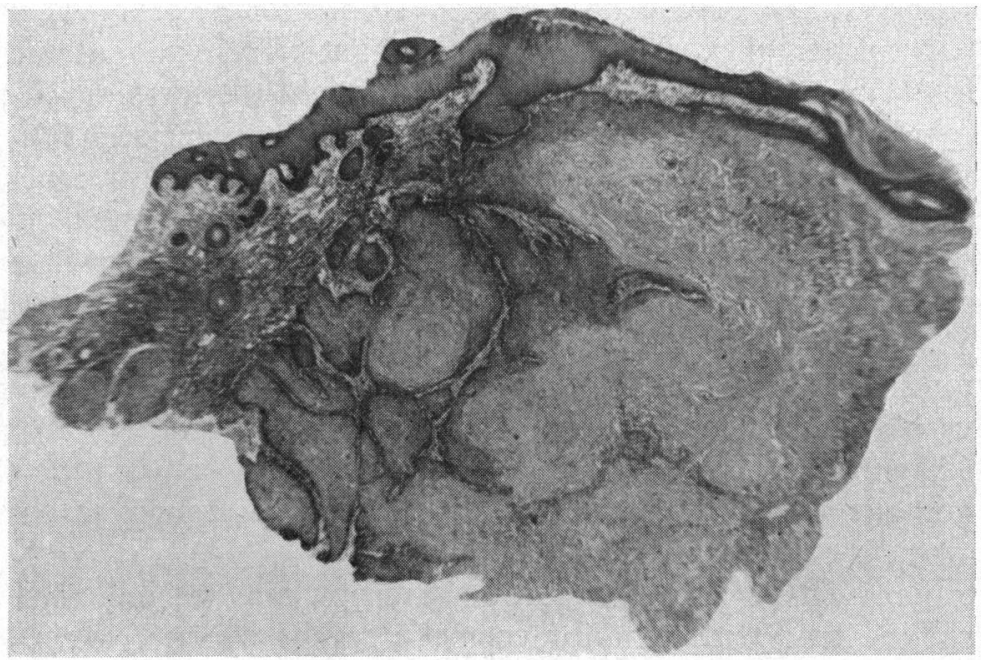

FIG. 3.-Second fragment in Case 1. Part of the main crater can be seen on the right. Haematoxylin and eosin. $\times 16$.

On sectioning, one of these showed part of the central crater on one side, containing keratin and parakeratin; this merged gradually with the lining acanthotic epithelium, forming large rounded masses extending deeply into the dermis (Figs 3 and 5).

The edge of the crater was marked by a thin spur (Fig. 4, opposite).

Although there was cellular atypicality (Fig. 6, opposite) this was not anaplastic in type. A chronic inflammatory reaction was present in the dermis, and the epidermaldermal junction was clearly defined (Figs 3, 5, and 6). The other fragment (Fig. 2) was similar but was cut more tangentially; it showed the tumour elements almost in contact at one edge with the conjunctival surface, which might suggest deep invasion; squamous carcinoma was, in fact, first diagnosed. 
Fig. 4.-Case 1. Thin lip or spur at the edge of crater. Haematoxylin and eosin. $\times 50$.


FIG. 5.-Case 1. Abundant parakeratosis which here constitutes most of the lesion. Haematoxylin and eosin. $\times 50$.

Fig. 6.-Case 1. Dyskeratosis and loss of cellular polarity. Note underlying chronic inflammation. Haematoxylin and eosin. $\times 430$.

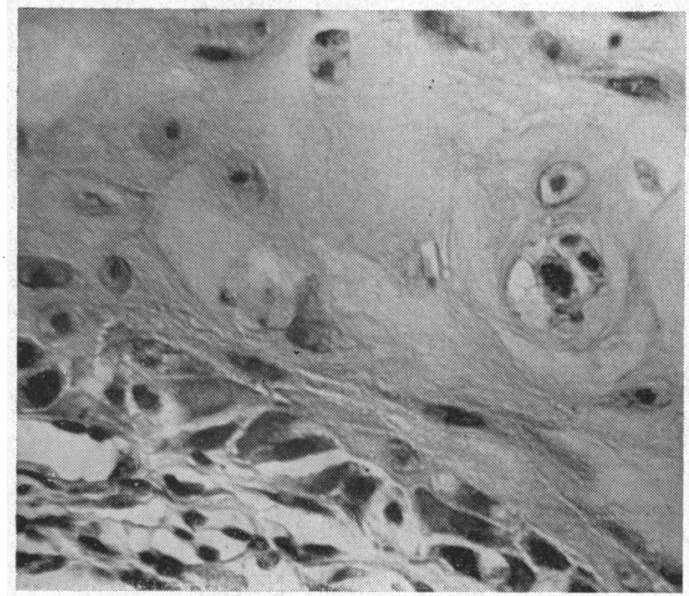

Case 2, a woman aged 61, presented with a mass on the left lower lid of 12 months' duration; this was excised under local anaesthesia and the diagnosis of kerato-acanthoma was suggested. The specimen measured $10 \times 6 \times 4 \mathrm{~mm}$. 
On microscopy the general appearance was that of a kerato-acanthoma, with the central crater containing keratin, the whole lesion being partly above and partly below the normal epidermal line (Fig. 7).

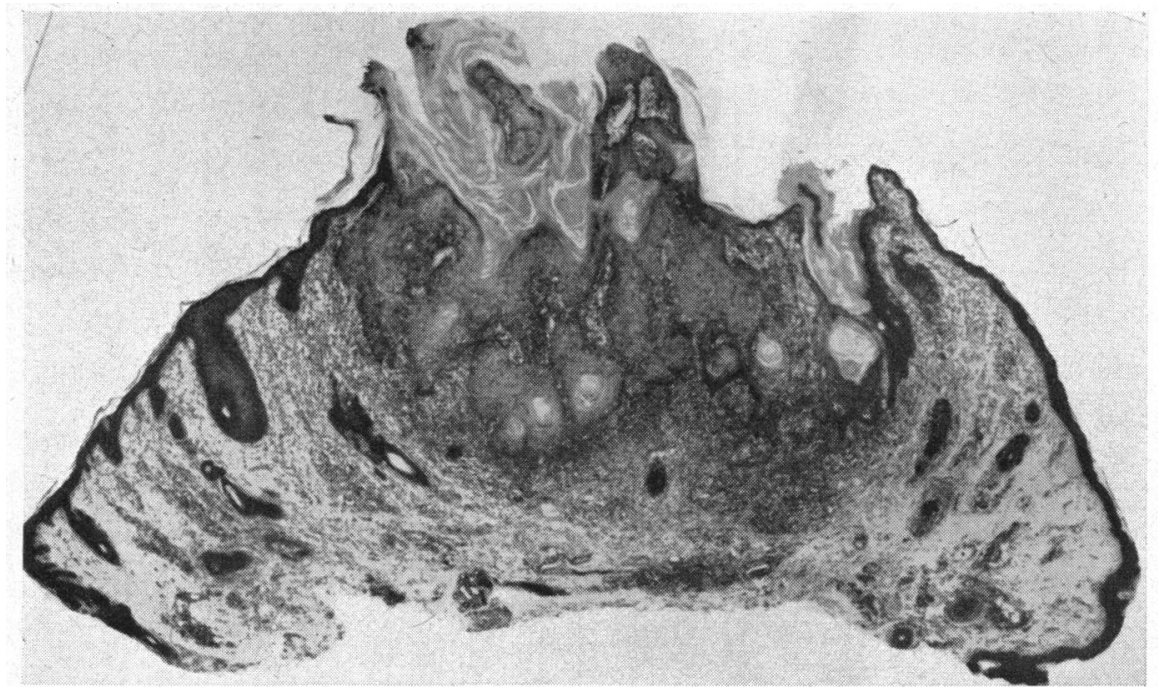

FIG. 7.-Case 2. General appearance characteristic of kerato-acanthoma. Intense underlying inflammatory reaction. Haematoxylin and eosin. $\times 24$.

The lining acanthotic epithelium was cellular and the general outline more ragged than in the previous example (Figs 8 and 9, opposite). Deep dyskeratosis was present, giving rise to epithelial pearls (Fig. 10, opposite). In spite of these architectural features, the cytology was not suggestive of malignancy. The dermal inflammatory reaction was heavy, consisting of lymphocytes, plasma cells, and a striking number of eosinophils, and this partly obscured the epidermal-dermal junction.

Case 3, a girl aged 14.-A small superficial excised plaque was received in the laboratory with a clinical diagnosis of chronic granuloma of the right lower lid.

The specimen measured $5 \times 4 \times 2 \mathrm{~mm}$. and on section was found to consist of part of a grossly acanthotic and dyskeratotic lesion containing a central enlarged follicle (Figs 11 and 12, overleaf). Although not anaplastic, the cytology was atypical, polarity being disturbed; epithelial pearls and examples of individual-cell keratinisation were present (Fig. 13, overleaf). The chronic inflammatory reaction was not prominent, but this may have been situated at a deeper level than that of the biopsy. The lesion subsequently healed without further treatment.

Experimental findings indicate the likelihood that the lesion arises in structures of the hair follicle, and that this may well have a bearing on the self-healing process, for if the neoplastic process develops in part of the follicle which is shed periodically, then the neoplasm may well be shed with it (Whiteley, 1957; Ghadially, 1958).

In conclusion, it should be stressed that kerato-acanthoma is not exceptional on the lid; in general, according to Borrie (1961), it is probably slightly commoner than epidermoid carcinoma. The fact that the lesion is benign 


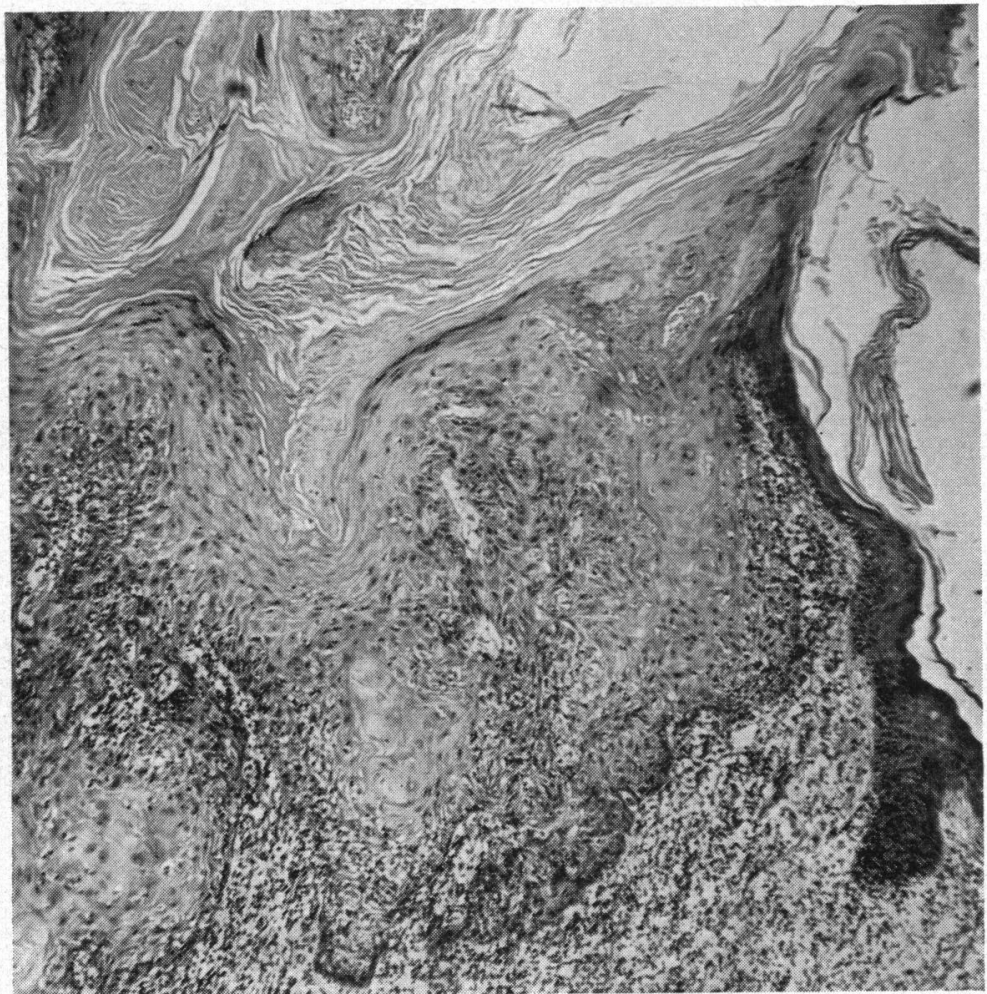

FIG. 8.-Case 2. Acanthosis is a more marked feature in this lesion. Appearances suggest pseudo-epitheliomatous hyperplasia. Haematoxylin and eosin. $\times 75$.

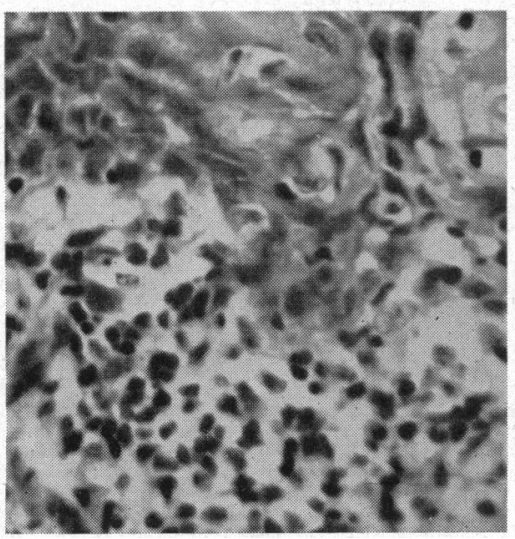

FIG. 9.-Case 2. Dermal-epidermal junction not as sharply defined as is usual in such lesions. Haematoxylin and eosin. $\times 430$.



FIG. 10.-Case 2. Deep rudimentary cell nest. Haematoxylin and eosin. $\times 360$. 


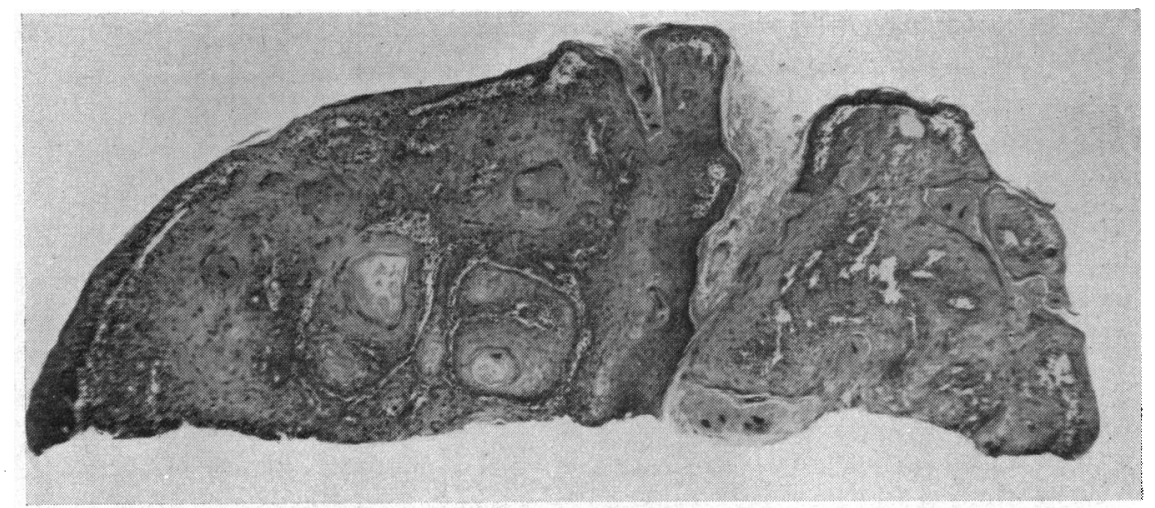

Fig. 11.-Case 3. Base-line is line of surgical excision showing that the lesion is not completely removed. Haematoxylin and eosin. $\times 32$.



Fig. 12.-Case 3. High-power view of enlarged follicle which alone represents the crater in this section. Haematoxylin and eosin. $\times 90$.

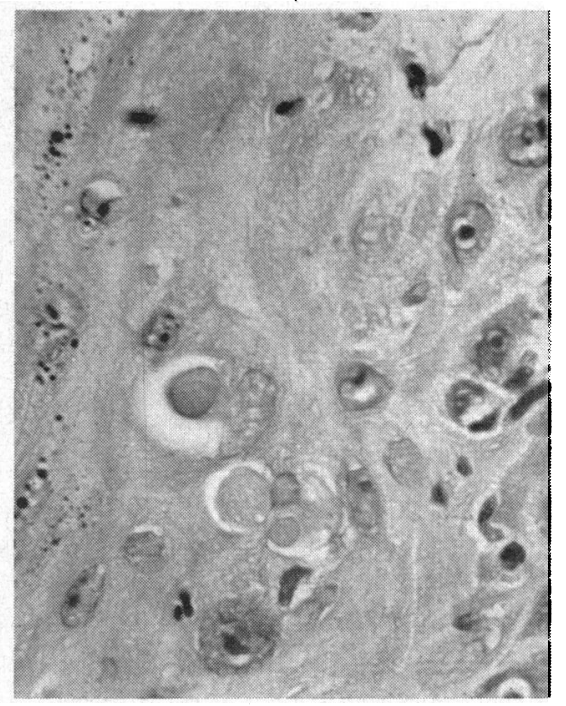

Fig. 13.-Case 3. Disorder of cellular polarity with individual cell keratinization. Haematoxylin and eosin. $\times 430$.

and self-healing, and is so easily confused with epidermoid carcinoma, has prompted this report which emphasizes the necessity for caution and awareness in interpreting biopsies from suspected neoplasms of the eyelid.

I am indebted to Professor Ashton for his help and encouragement in the preparation of this paper, and to the staff of the Department of Pathology and the Department of Medical Illustration at the Institute of Ophthalmology. I should also like to thank Dr. H. Haber for his considerable help, and Dr. P. Borrie for very kindly supplying the clinical photograph prepared by the Department of Medical Photography at St. Bartholomew's Hospital. 


\section{REFERENCES}

BeARE, J. M. (1953). Brit. J. Surg., 41, 167.

BORRIE, P. (1961). "Roxburgh's Common Skin Diseases". 12th ed., p. $430 . \quad$ Lewis, London. (Revised).

Calnan, C. D., and Haber, H. (1955). J. Path. Bact., 69, 61.

Christensen, L., and FitzPATRICK, T. B. (1955). Arch. Ophthal. (Chicago), 53, 857.

CURRIE, A. R., and SMITH, J. Ferguson (1952). J. Path. Bact., 64, 827.

Freeman, R. G., Cloud, T. M., and KnOX, J. M. (1961). Arch. Ophthal. (Chicago), 65, 817.

Ghadially, F. N. (1958). J. Path. Bact. 75, 441.

Givner, I., Kallos, A., Medine, M., and ORfuss, A. J. (1960). Amer. J. Ophthal., 49, 822.

LennoX, B. (1960). In "Recent Advances in Pathology", 7th ed., ed. C. V. Harrison, p. 1. Churchill, London.

LINELl, F., and MÅnsSON, B. (1957). Acta radiol, (Stockh.), 48, 123.

MaCCormaC, H., and SCARF, R. W. (1936). Brit.J. Derm., 48, 624.

Musso, L. (for Gordon, H.) (1950). Proc. roy. Soc. Med., 43, 838.

ROOK, A., and Whimster, I. (1950). Arch. belg. Derm., 6, 137.

SMITH, J. Ferguson (1934). Brit. J. Derm., 46, 267.

Whiteley, H. J. (1957). Brit. J. Cancer, 11, 196.

\section{NOTE}

Since this paper was submitted for publication, six further cases of kerato-acanthoma of the lid have been examined in this Department. 